\title{
Management of obstructive sleep apnea/hypopnea syndrome in neurocognitive disorders
}

\author{
Joel Barrett MD, Ashish Sarangi MD, Jessica Nelson MD
}

\begin{abstract}
Obstructive sleep apnea/hypopnea syndrome (OSAHS) has important implications in afflicted patients' overall management from critical care units to outpatient clinics. This clinical review addresses up-to-date recommendations from professional organizations, such as the American Academy of Sleep Medicine, and puts management in context of patients with comorbid neurocognitive disorders (such as vascular or Alzheimer's dementia). For example, recent studies have found a potential bidirectional relationship between the disease process OSAHS and neurocognitive disorders or other psychiatric disorders found in older people. It is important to consider possible general medical and psychiatric contributors to severity of OSAHS, particularly in geriatric patients.
\end{abstract}

Keywords: Sleep apnea, obstructive; neurocognitive disorders; Alzheimer disease; depressive disorder, major

\section{INTRODUCTION}

Obstructive sleep apnea/hypopnea syndrome (OSAHS) is a primary sleep disorder with disordered breathing that has significant ramifications in cardiac, neurologic, and psychiatric disorders. The primary symptoms of OSAHS are nocturnal breathing disturbances (such as snoring or pauses of breathing during sleep) or excessive daytime sleepiness and otherwise unrefreshing sleep. ${ }^{1}$ The pathophysiology of this disorder explains its impact on a range of body systems, which results from episodes of reduced ventilation for at least 10 seconds and is commonly associated $\geq 3 \%$ drop in oxygen saturation or interrupted sleep. ${ }^{1}$ The reduced ventilation contributes to a buildup of carbon dioxide $\left(\mathrm{CO}_{2}\right)$, further complicating ventilatory control during sleep and resulting in central nervous system (CNS) arousal. The CNS arousal can either contribute to nocturnal awakenings or fragmentation of normal

Corresponding author: Joel Barrett

Contact Information: Joel.Barrett@ttuhsc.edu

DOI: 10.12746/swrccc.v9i39.849 sleep stages. The improper ventilation associated with OSAHS also explains its impact upon cardiovascular health by disrupting autonomic fluctuations and hemodynamic changes associated with normal sleep that are typically cardioprotective. ${ }^{2}$ The range of adverse cardiovascular effects includes hypertension, cardiac arrhythmias, pulmonary hypertension, coronary artery disease, and stroke. ${ }^{1}$

There is a consensus in the literature that OSAHS is associated with advanced age and to a greater extent in patients with neurocognitive disorders, such as Alzheimer's dementia. Further discussion of the pathophysiology and importance of addressing OSAHS in patients with neurocognitive disorders specifically is discussed later in this review. Despite the association between OSAHS and dementia disorders, studies regarding the prevalence of OSAHS in patients with dementia are limited. A 1991 study found that $43 \%$ of 235 studied individuals ages 65 -years-old and older admitted to a skilled nursing facility had an apnea index $\geq 5$ and $60 \%$ and $>5$ respiratory disturbance index. ${ }^{3}$ In this same sample, $96 \%$ of patients able to complete the Mattis Dementia Rating Scale showed some dementia (score $<145$ ). 
A more recent Italian multi-center study in 2012 found the prevalence of sleep-disordered breathing up to $60 \%$ in a population consisting of individuals with mild cognitive impairment and other dementias. ${ }^{4} \mathrm{~A}$ more recent metanalysis of 5 cross-sectional studies in 2016 found that there is a 5.05 aggregate odds ratio in 90 patients affected by Alzheimer's dementia relative to 146 healthy controls. ${ }^{5}$

Addressing OSAHS in patients with neurocognitive dysfunction requires a multi-tiered approach, which includes assessing for and treating: 1. any other comorbid primary sleep disorders (such as obstructive sleep apnea), 2. psychiatric comorbidities, and 3. associated symptoms or medical conditions that secondarily interrupt sleep quality. ${ }^{6}$ The management of OSAHS is discussed elsewhere. ${ }^{1,7}$ The remainder of this article will discuss the management of psychiatric comorbidities and associated symptoms or medical disorders that secondarily interrupt sleep quality.

\section{COMORBID PRIMARY SLEEP DISORDERS}

Besides OSAHS, other primary sleep disorders that are critical to address include rapid eye movement (REM) sleep disorders, insomnia, and hypersomnia (Table 1). ${ }^{6,8}$ When managing restless leg syndrome, consideration of a pre-existing major depressive disorder diagnosis may guide therapy to dopamine agonists after a trial of iron replacement therapy. ${ }^{9}$ It can be important to consider the possibility of insomnia or hypersomnia as a second diagnosis in some patients with OSAHS. An insomnia disorder should be considered when there is significant delay in sleep onset in patients, which would contribute to symptoms found in patients with OSAHS. Excessive daytime sleepiness that is strongly associated with the poor sleep quality resembles hypersomnia clinically but may lack risk factors, such as obesity or symptoms, such as loud snoring or pauses in breathing during sleep seen in OSAHS. Therefore, persistent hypersomnia that is not associated with characteristic sleep changes by polysomnography in a sleep study or otherwise not responsive to CPAP should prompt re-evaluation for a hypersomnolence disorder. ${ }^{8}$

Cognitive behavioral therapy for insomnia (CBT-I) has the strongest evidence for efficacy among other non-pharmacologic interventions for primary insomnia in the general adult population. ${ }^{10}$ Cognitive behavioral therapy for insomnia involves a multimodal approach that optimizes patients' attitudes and thoughts regarding sleep and introduces behavioral interventions commonly referred to as "sleep hygiene" (such as sleep restriction, stimulus control). Cognitive behavioral therapy for insomnia also improves CPAP adherence based on a 2019 study which included 145 patients with OSAHS. ${ }^{11}$ This is promising since CBT-I is a leading nonpharmacologic intervention for patients with insomnia. There are free online CBT-I programs available in smartphone app form, of which CBT-I Coach developed by the Veteran Affairs Health Care System was found to be superior in usability and implementation of CBT-I among 12 other insomnia therapy smartphone apps. $^{12}$

When considering pharmacologic agents for a condition, such as primary insomnia, trazodone is generally tolerated well in patients with neurodegenerative disorders, such as Alzheimer's dementia, and did not increase hypoxemia in a small 2015 study of 15 patients with OSAHS. ${ }^{13}$ The use of benzodiazepines and other sedatives in patients with neurocognitive disorders is strongly discouraged due to the increased risk of causing more cognitive impairment and an increased risk of delirium. ${ }^{14}$ Overall the evidence supporting pharmacotherapies is limited in patients affected by neurocognitive disorders secondary to Alzheimer's dementia and was reviewed in a recent Cochrane review of pharmacotherapies for sleep disturbances in Alzheimer's disease. ${ }^{15}$ Only melatonin, trazodone, and ramelteon met inclusion criteria in this review. Melatonin and ramelteon did not have significant benefit in patients with Alzheimer's disease. Only trazodone at $50 \mathrm{mg}$ showed definite benefit, but larger studies are needed to thoroughly evaluate risks and benefits in these patients. The tricyclic antidepressant, doxepin, is the only drug in its class at low doses ( $\leq 6 \mathrm{mg} /$ day) which has a safety profile comparable to placebo. ${ }^{14}$ Other tricyclic antidepressants are considered a safety concern in these patients for treatment of insomnia, due to being highly anticholinergic and causing orthostatic hypotension. Mirtazapine is an antidepressant that is well tolerated in older patients with depression complicated by insomnia and weight loss; however, studies are limited on its possible benefits for insomnia in patients with Alzheimer's dementia. 
Table 1. Review of Pertinent Comorbidities or Contributors to Poor Sleep Quality and Relationship with OSAHS

\begin{tabular}{|c|c|c|c|}
\hline & RELATIONSHIP & MANAGEMENT & REFERENCES \\
\hline \multicolumn{4}{|l|}{ SLEEP QUALITY MODIFIERS } \\
\hline $\begin{array}{l}\text { NOCTURIA } \\
\text { BPH } \\
\text { OAB }\end{array}$ & Interferes with sleep & \begin{tabular}{|l|} 
Nonpharmacologic \\
interventions \\
$\alpha-1$-inhibitors, Surgery \\
Antimuscarinics \\
\end{tabular} & Kowalik, et al. $(2018)^{37}$ \\
\hline $\begin{array}{l}\text { RESTLESS LEG SYNDROME } \\
\text { MILD } \\
\text { CORMOBID NEUROPATHY } \\
\text { SEVERE } \\
\text { COMORBID MDD OR DM }\end{array}$ & Interferes with sleep & $\begin{array}{l}\text { Iron Supplementation } \\
\alpha-2-\delta \text { Calcium Channel } \\
\text { Ligands } \\
\alpha-2-\delta \text { Calcium Channel } \\
\text { Ligands } \\
\text { Dopamine Agonists } \\
\text { Dopamine Agonists }\end{array}$ & $\begin{array}{l}\text { Reviewed by Ooms \& } \\
\text { Ju }(2016)^{6} \\
\text { AASM Guidelines }(2012)^{38} \\
\text { Garcia-Borreguero, et al. } \\
(2013)^{9}\end{array}$ \\
\hline \multicolumn{4}{|l|}{ PRIMARY SLEEP DISORDERS } \\
\hline INSOMNIA & $\begin{array}{l}\text { Can be comorbid with } \\
\text { OSAHS and worsen } \\
\text { symptomatology by delay } \\
\text { of sleep onset, for example }\end{array}$ & $\begin{array}{l}\text { Sleep hygiene, CBT-I } \\
\text { Trazodone } \\
\text { Sedatives with caution }\end{array}$ & $\begin{array}{l}\text { Sweetman, et al. }(2019)^{11} \\
\text { Smales, et al. }(2015)^{13}\end{array}$ \\
\hline PRIMARY REM DISORDERS & Interferes with sleep & $\begin{array}{l}\text { Trazodone } \\
\text { Sedative medications should } \\
\text { be used with caution }\end{array}$ & Smales, et al. $(2015)^{13}$ \\
\hline \multicolumn{4}{|l|}{ PSYCHIATRIC DISORDERS } \\
\hline ALZHEIMER'S DEMENTIA & $\begin{array}{l}\text { Possibly bidirectional in } \\
\text { terms of Alzheimer's } \\
\text { dementia and OSAHS } \\
\text { severity }\end{array}$ & Reviewed elsewhere & $\begin{array}{l}\text { Osorio, et al. }(2015)^{24} \\
\text { Reviewed by Ooms \& } \\
\quad \mathrm{Ju}(2016)^{6}\end{array}$ \\
\hline VASCULAR DEMENTIA & $\begin{array}{l}\text { OSAHS is a contributor } \\
\text { to vascular events that } \\
\text { precipitate Vascular } \\
\text { dementia }\end{array}$ & $\begin{array}{l}\text { Addressing vascular } \\
\text { risk factors (e.g., } \\
\text { dyslipidemia, } \\
\text { hypertension, or OSAHS) }\end{array}$ & $\begin{array}{l}\text { Kim, et al. }(2013)^{23} \\
\text { Reviewed in }\end{array}$ \\
\hline $\begin{array}{l}\text { MAJOR DEPRESSIVE } \\
\text { DISORDER }\end{array}$ & $\begin{array}{l}\text { Median prevalence of } 48.1 \% \\
\text { Possible bidirectional } \\
\text { relationship between } \\
\text { MDD and OSAHS. }\end{array}$ & $\begin{array}{l}\text { Anti-depressants } \\
\text { Such as, mirtazapine in } \\
\text { depression complicated by } \\
\text { insomnia and weight loss }\end{array}$ & $\begin{array}{l}\text { Reviewed in }{ }^{21} \\
\text { Edwards, et al. }(2015)^{28} \\
\text { Gagnadoux, et al. }(2014)^{29} \\
\text { Habukawa, et al. }(2010)^{30} \\
\text { Schwartz, et al. }(2005)^{31}\end{array}$ \\
\hline
\end{tabular}

Abbreviations: AASM = American Academy of Sleep Medicine, ADA = American Diabetes Association; AHA = American Heart Association; BPH = Benign prostatic hyperplasia; CBT-I: Cognitive behavioral therapy for insomnia; $\mathrm{DM}=$ Diabetes mellitus; $\mathrm{MDD}=$ Major depressive disorder; $\mathrm{OAB}=\mathrm{Overactive}$ bladder.

Suvorexant is an orexin receptor antagonist that has demonstrated efficacy in treating insomnia in adults, including those of older age. ${ }^{16,17} \mathrm{~A}$ recent study using polysomnography assessment of suvorexant in patients with probable Alzheimer's disease and comorbid insomnia found improvements in mean total sleep time of 28 minutes, which exceeds the American Academy of Sleep Medicine's recommendation of 20 minutes for clinically significant differences in comparison to placebo. ${ }^{18}$ With more studies 


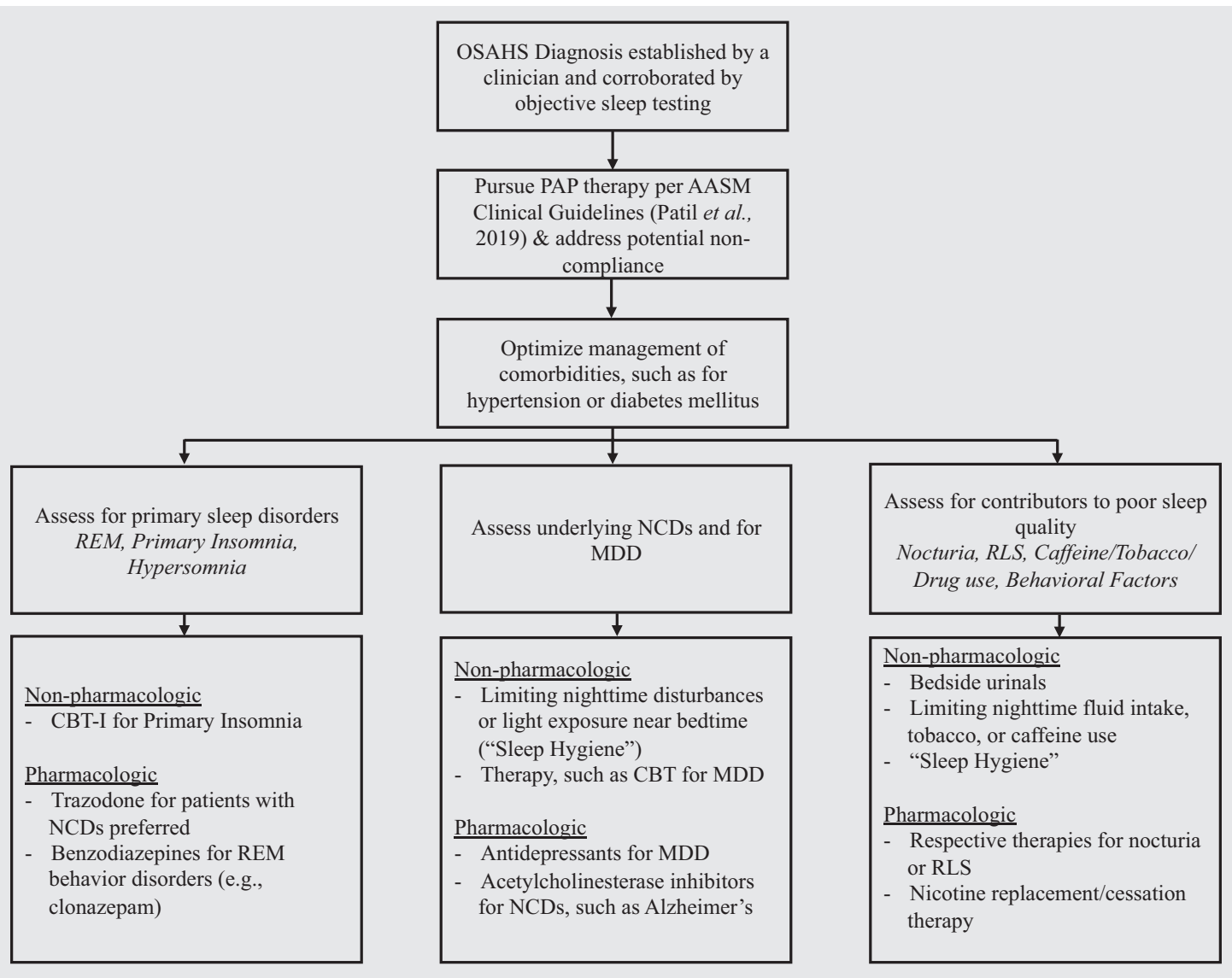

Figure 1. Algorithm integrating management of contributors to reduced sleep quality characteristic of OSAHS. Adapted and modified from SP Patil, et al. (2019), the Clinical Practice Guideline from the AASM. * = Benzodiazepines should be avoided or used in caution in patients with NCDs.

Abbreviations: AASM = American Academy of Sleep Medicine; CBT-I = Cognitive behavioral therapy for insomnia; MDD = Major depressive disorder; OSAHS = Obstructive sleep apnea hypopnea syndrome; PAP = Positive airway pressure; REM = Rapid eye movement stage sleep disorders; RLS = Restless leg syndrome.

in patients with neurocognitive disorders, pharmacologic agents with more evidence for benefit in insomnia may be identified.

\section{PsychiatRIC COMORBIDITIES}

A consensus of literature links OSAHS and multiple types of psychiatric disorders, which range from neurocognitive disorders (NCD) to mood disorders. ${ }^{19,20}$ Besides the direct effect of excessive daytime sleepiness upon cognitive functioning, the abnormal sleep fragmentation found in OSAHS may have long term effects upon neurocognitive functioning by dysregulating cerebral microvascular and neurovascular systems by hypoperfusion, endothelial dysfunction, and neuroinflammation. ${ }^{21}$ Dysregulation of cerebral vascular systems is associated with neurovascular comorbidities, such as cerebrovascular accidents (CVA), that directly contribute to the stepwise progression of major or minor vascular NCD. ${ }^{22}$ Notably, the severity of OSAHS symptoms has been reported to be an independent risk factor for cerebral white matter changes identified by brain magnetic resonance imaging that are typically prodromal of vascular NCD. ${ }^{23}$ The effects of 
OSAHS is not isolated to major or minor vascular NCD. There are also demonstrated associations with NCD due to Alzheimer's disease. A significant study, which was a secondary analysis of the Alzheimer's Disease Neuroimaging Initiative cohort, was published in 2015 and demonstrated that OSAHS was associated with an earlier onset of cognitive decline. ${ }^{24}$ Further, the study's findings of patients that were on continuous positive airway pressure (CPAP) suggested that CPAP treatment of OSAHS may delay progression of cognitive impairment. A recent review in the Journal of Alzheimer's Disease (2019) discussed mechanisms which included basic science evidence that OSAHS may potentiate neuropathological mechanisms that increase severity of Alzheimer's dementia (e.g., through the chronic effects of the disruption of sleep architecture and neuroinflammatory processes) ${ }^{25}$

A complete history is necessary for the assessment of sleep and circadian disturbances in any population, including those affected by dementia. Given that some demented patients may not recall symptoms accurately, a collateral history of symptoms suggestive of primary sleep disorders from caregivers is essential. ${ }^{6}$ Similarly, there are barriers to CPAP compliance in patients with neurocognitive disorders such as dementias. Barriers may be addressed by educating caregivers on the proper use. In a study that analyzed CPAP compliance in 30 patients with Alzheimer's dementia randomized to sham and CPAP, patients with Alzheimer's dementia wore CPAP for an average of 4.8 hours per night at home. ${ }^{26}$ Notably, the severity of dementia symptoms was not correlated with CPAP compliance.

The associated sleep disturbances and decreased energy in OSAHS can contribute to major depressive disorder, and multiple studies have demonstrated this objectively as recently reviewed by Kerner and Roose (2016) in the American Journal of Geriatric Psychiatry. ${ }^{21}$ The literature collectively suggests a bidirectional interaction between management of major depressive disorder and OSAHS in geriatric patients. For example, treatment of depression with antidepressants in patients with comorbid OSAHS resulted in improvement in cerebrovascular reactivity by neuroimaging, which is indirectly associated with improvement of OSAHS symptoms. ${ }^{27}$ Compliance with CPAP alone in patients with comorbid OSAHS has been found to significantly improve depressive symptoms in several studies by patient rated depression scales. ${ }^{28-31}$ A 2008 case report exemplified the importance of assessing for comorbid sleep disorders as contributors to the symptoms associated with depression, such as suicidal ideation. This patient had a rapid resolution suicidal ideation in the setting of obstructive sleep apnea with initiation of CPAP even without the administration of an antidepressant medication. ${ }^{32}$

\section{OTHER COMORBIDITIES OR CONTRIBUTORS TO REDUCED SLEEP QUALITY}

There are other comorbidities in these patients that contribute to poor outcomes or sleep disturbances (Table 1). ${ }^{6,33}$ This includes addressing comorbidities or concomitant factors, as reviewed elsewhere, such as hypertension, ${ }^{34}$ dyslipidemia, ${ }^{35}$ diabetes mellitus, ${ }^{36}$ inadequate pain management, nocturia, ${ }^{37}$ restless leg syndrome,${ }^{9,38}$ use of substances that interact with sleep (e.g., tobacco, alcohol, caffeine), and light or noise exposure in the evening. Symptoms, such as nocturia, can be addressed without medication by limiting of nighttime fluid intake and daily caffeine intake and using bedside urinals. ${ }^{37}$ However, the diagnosis and treatment of the underlying condition (such as benign prostatic hyperplasia or overactive bladder) may be necessary. ${ }^{37}$

\section{Conclusions}

It is important to address previously diagnosed or suspected OSAHS in patients in clinical settings that range from critical care units to outpatient clinics. While a recent study has found that OSAHS may not be an independent risk factor for the incidence of post-operative/critical care delirium, the current consensus of the literature suggests that both the mechanisms and severity of OSAHS are associated with prolonged duration of delirium in the critical care setting. For outpatient management, OSAHS is a definite contributor to increased mortality through its effects on multiple body systems. Considering these findings, ${ }^{39-41}$ the authors of this review can make some 
recommendations to consider treatment of psychiatric comorbidities when no improvements are observed within one month of initiating CPAP. In patients with depressive symptoms consisting primarily of fatigue, decreased energy, and concentration in the setting of sleep disturbances, the authors of this review recommend initiating separate treatment for depression by 1 month. The presence of anhedonia or suicidality, even within one month of initiating CPAP, should prompt initiation of treatment for depression or an emergent referral to an inpatient facility, respectively. Persistent neurocognitive deficits either confirmed by neuropsychologic testing or MMSE one month after initiation of CPAP should prompt further evaluation of a separate neurocognitive disorder. Clinicians need to remember the importance of addressing other possible general medical and psychiatric contributors to severity of OSAHS, particularly in geriatric patients.

\section{Article citation: Barrett J, Sarangi A, Nelson J. Management of obstructive sleep apnea/hypopnea syndrome in neurocognitive disorders. The Southwest Respiratory and Critical Care Chronicles 2021;9(39):41-47 From: Department of Psychiatry, Texas Tech University Health Sciences Center, Lubbock, Texas \\ Submitted: 9/22/2021 \\ Accepted: 4/4/2021 \\ Reviewer: Kenneth Nugent MD \\ Conflicts of interest: none}

This work is licensed under a Creative Commons

Attribution-ShareAlike 4.0 International License.

\section{REFERENCES}

1. Wellman A, Redline S. Sleep Apnea. In: Jameson JL, Fauci AS, Kasper DL, Hauser SL, Longo DL, Loscalzo J, editors. Harrison's Principles of Internal Medicine, 20e. New York, NY: McGraw-Hill Education; 2018.

2. Mehra R. Sleep apnea and the heart. Cleve Clin J Med 2019; 86(9 Suppl 1):10-8.

3. Ancoli-Israel S, Klauber MR, Butters N, et al. Dementia in institutionalized elderly: relation to sleep apnea. J Am Geriatr Soc 1991;39(3):258-63.

4. Guarnieri B, Adorni F, Musicco M, et al. Prevalence of sleep disturbances in mild cognitive impairment and dementing disorders: a multicenter Italian clinical cross-sectional study on 431 patients. Dement Geriatr Cogn Disord 2012;33(1):50-8.

5. Emamian F, Khazaie H, Tahmasian M, et al. The association between obstructive sleep apnea and alzheimer's disease: a meta-analysis perspective. Front Aging Neurosci 2016;8:78. Epub 2016/05/06. doi: 10.3389/fnagi.2016.00078.

6. Ooms S, Ju YE. Treatment of sleep disorders in dementia. Curr Treat Options Neurol 2016;18(9):40. Epub 2016/08/01. doi: 10.1007/s1 1940-016-0424-3.

7. Patil SP, Ayappa IA, Caples SM, et al. Treatment of adult obstructive sleep apnea with positive airway pressure: An American Academy of Sleep Medicine Clinical Practice Guideline. J Clin Sleep Med. 2019;15(2):335-43.

8. Sleep-Wake Disorders. Diagnostic and Statistical Manual of Mental Disorders.

9. Garcia-Borreguero D, Kohnen R, Silber MH, et al. The longterm treatment of restless legs syndrome/Willis-Ekbom disease: evidence-based guidelines and clinical consensus best practice guidance: a report from the International Restless Legs Syndrome Study Group. Sleep Med 2013;14(7):675-84.

10. Brasure M, Fuchs E, MacDonald R, et al. Psychological and behavioral interventions for managing insomnia disorder: an evidence report for a Clinical Practice Guideline by the American College of Physicians. Ann Intern Med 2016; 165(2):113-24.

11. Sweetman A, Lack L, Catcheside PG, et al. Cognitive and behavioral therapy for insomnia increases the use of continuous positive airway pressure therapy in obstructive sleep apnea participants with comorbid insomnia: a randomized clinical trial. Sleep 2019;42(12). Epub 2019/08/14. doi: 10.1093/sleep/ zsz178. PubMed PMID: 31403168.

12. Yu JS, Kuhn E, Miller KE, et al. Smartphone apps for insomnia: examining existing apps' usability and adherence to evidence-based principles for insomnia management. Transl Behav Med 2019;9(1):110.

13. Smales ET, Edwards BA, Deyoung PN, et al. Trazodone effects on obstructive sleep apnea and non-REM arousal threshold. Ann Am Thorac Soc 2015;12(5):758-64.

14. Roth $T$, Brunton $S$. Identification and management of insomnia in Alzheimer's Disease. J Fam Pract 2019;68(8).

15. McCleery J, Cohen DA, Sharpley AL, et al. Pharmacotherapies for sleep disturbances in Alzheimer's disease. Cochrane Database of Systematic Reviews 2014.

16. Herring WJ, Connor KM, Ivgy-May N, et al. Suvorexant in patients with insomnia: results from two 3-month randomized controlled clinical trials. Biological Psychiatry 2016; 79(2):136-48.

17. Herring WJ, Connor KM, Snyder E, et al. Suvorexant in elderly patients with insomnia: pooled analyses of data from 
phase iii randomized controlled clinical trials. American J Geriatric Psychiatry 2017;25(7):791-802.

18. Herring WJ, Ceesay P, Snyder E, et al. Polysomnographic assessment of suvorexant in patients with probable Alzheimer's disease dementia and insomnia: a randomized trial. Alzheimer's \& Dementia 2020;16(3):541-51.

19. Engleman HM, Douglas NJ. Sleep. 4: Sleepiness, cognitive function, and quality of life in obstructive sleep apnoea/ hypopnoea syndrome. Thorax 2004;59(7):618-22.

20. Beebe DW, Groesz L, Wells C, et al. The neuropsychological effects of obstructive sleep apnea: a meta-analysis of norm-referenced and case-controlled data. Sleep 2003;26(3): 298-307.

21. Kerner NA, Roose SP. Obstructive sleep apnea is linked to depression and cognitive impairment: evidence and potential mechanisms. Am J Geriatr Psychiatry 2016;24(6): 496-508.

22. Neurocognitive Disorders. Diagnostic and Statistical Manual of Mental Disorders. DSM Library: American Psychiatric Association; 2013.

23. Kim H, Yun CH, Thomas RJ, et al. Obstructive sleep apnea as a risk factor for cerebral white matter change in a middle-aged and older general population. Sleep 2013;36(5):709-15B.

24. Osorio RS, Gumb T, Pirraglia E, et al. Sleep-disordered breathing advances cognitive decline in the elderly. Neurology 2015;84(19):1964-71.

25. Andrade AG, Bubu OM, Varga AW, et al. The relationship between obstructive sleep apnea and Alzheimer's Disease. J Alzheimers Dis 2018;64(s1):S255-S70.

26. Ayalon L, Ancoli-Israel S, Stepnowsky C, et al. Adherence to continuous positive airway pressure treatment in patients with Alzheimer's disease and obstructive sleep apnea. Am J Geriatr Psychiatry 2006;14(2):176-80.

27. de Castro AG, Bajbouj M, Schlattmann P, et al. Cerebrovascular reactivity in depressed patients without vascular risk factors. J Psychiatr Res 2008;42(1):78-82.

28. Edwards C, Mukherjee S, Simpson L,et al. Depressive symptoms before and after treatment of obstructive sleep apnea in men and women. J Clin Sleep Med. 2015;11(9): 1029-38.

29. Gagnadoux F, Le Vaillant M, Goupil F, et al. Depressive symptoms before and after long-term CPAP therapy in patients with sleep apnea. Chest 2014;145(5):1025-31.

30. Habukawa M, Uchimura N, Kakuma T, et al. Effect of CPAP treatment on residual depressive symptoms in patients with major depression and coexisting sleep apnea: Contribution of daytime sleepiness to residual depressive symptoms. Sleep Med 2010;11(6):552-7.

31. Schwartz DJ, Kohler WC, Karatinos G. Symptoms of depression in individuals with obstructive sleep apnea may be amenable to treatment with continuous positive airway pressure. Chest 2005;128(3):1304-9.

32. Krahn LE, Miller BW, Bergstrom LR. Rapid resolution of intense suicidal ideation after treatment of severe obstructive sleep apnea. J Clin Sleep Med 2008;4(1):64-5.

33. Marin-Oto M, Vicente EE, Marin JM. Long term management of obstructive sleep apnea and its comorbidities. Multidiscip Respir Med 2019;14:21. Epub 2019/07/18. doi: 10.1186/s40248-019-0186-3.

34. Unger $T$, Borghi $C$, Charchar F, et al. 2020 International Society of Hypertension Global Hypertension Practice Guidelines. Hypertension 2020;75(6):1334-57.

35. Grundy SM, Stone NJ, Bailey AL, et al. $2018 \mathrm{AHA} / \mathrm{ACC} /$ AACVPR/AAPA/ABC/ACPM/ADA/AGS/APhA/ASPC/ NLA/PCNA Guideline on the Management of Blood Cholesterol: A Report of the American College of Cardiology/ American Heart Association Task Force on Clinical Practice Guidelines. Circulation 2019;139(25):e1082-e143.

36. American Diabetes A. Standards of Medical Care in Diabetes2020 Abridged for Primary Care Providers. Clin Diabetes 2020;38(1):10-38.

37. Kowalik CG, Cohn JA, Delpe S, et al. Nocturia: evaluation and current management strategies. Rev Urol 2018;20(1):1-6.

38. Aurora RN, Kristo DA, Bista SR, et al. The treatment of restless legs syndrome and periodic limb movement disorder in adults-an update for 2012: practice parameters with an evidence-based systematic review and meta-analyses: an American Academy of Sleep Medicine Clinical Practice Guideline. Sleep 2012;35(8):1039-62.

39. Olaithe M, Bucks RS. Executive dysfunction in OSA before and after treatment: a meta-analysis. Sleep 2013;36(9): 1297-305.

40. Kushida CA, Nichols DA, Holmes TH, et al. Effects of continuous positive airway pressure on neurocognitive function in obstructive sleep apnea patients: The Apnea Positive Pressure Long-term Efficacy Study (APPLES). Sleep 2012; 35(12):1593-602.

41. Zheng D, Xu Y, You S, et al. Effects of continuous positive airway pressure on depression and anxiety symptoms in patients with obstructive sleep apnoea: results from the sleep apnoea cardiovascular Endpoint randomised trial and meta-analysis. EClinicalMedicine 2019;11:89-96. 